\title{
Gender Differences in Statistics Anxiety with Undergraduate College Students
}

\author{
Dr. Nina B. Eduljee ${ }^{1}$, Pamela LeBourdais ${ }^{2}$
}

\section{ABSTRACT:}

This empirical study examined gender differences in statistics anxiety with 156 undergraduate college students (48 males, 107 females) from a liberal arts college in the United States. Students completed surveys regarding number of prior statistics classes completed and statistics anxiety. Three subscales of the Statistical Anxiety Rating Scale (STARS; Cruise, Cash, and Bolton, 1985) which measures statistics anxiety were used. No gender differences were obtained for the Worth of Statistics and Computation Self-Concept subscales. Females had greater anxiety on the Test and Class Anxiety subscale than males. For males, no significant correlations were obtained between statistics anxiety and course grades. For females, significant correlations were obtained between Worth of Statistics and course grades $(r=.230, p<.05)$ and Computation Self-Concept and course grades $(r=.226, \mathrm{p}<.05)$.

Keywords: Statistics anxiety, Gender differences, Undergraduate college students

College students are required to enroll in a statistics class as part of their degree program (Finch \& Jameson, 2007; Hilton, Schau, \& Olsen, 2004; Keeley, Zayac, \& Correia, 2008; Onwuegbuzie \& Wilson, 2003; Zeidner, 1991). Many of these student often experience statistics anxiety (Hsiao \& Chiang, 2011; Mji \& Onwuegbuzie, 2004), because "statistics courses are often viewed by most college students as an obstacle standing in the way of attaining their desired degree" (Perney \& Ravid, 1990, p. 2). Williams (2010) indicates that "students with statistics anxiety tend to expect high levels of discomfort while in class, taking tests, and doing statistical computations" (p. 13). Since taking a statistics course is often an overwhelming negative experience, many students delay taking a statistics class, which in turn delays the attainment of the educational degree (Finch \& Jameson, 2007; Galli, Ciancaleoni, Chiesi, \& Primi, 2008; Onwuegbuzie \& Wilson, 2003). Thus, understanding about a student's level of anxiety that may be generated through statistics classes may help college professors find ways to reduce the level of anxiety and enhance the learning experienced by their students (Baharun \& Porter, 2009).

\footnotetext{
${ }^{1}$ Professor, Saint Joseph's College of Maine, 461 Alfond Hall, 278 Whites Bridge Road, Standish, ME 04084, USA

${ }^{2}$ University of Southern Maine at Lewiston-Auburn College, 51 Westminster Street, Lewiston, ME 04240, USA

(C) 2015 I N Eduljee, P Lebourdais; licensee IJIP. This is an Open Access Research distributed under the terms of the Creative Commons Attribution License (http://creativecommons.org/licenses/by/2.0), which permits unrestricted use, distribution, and reproduction in any Medium, provided the original work is properly cited.
} 
Cruise, Cash \& Bolton (1985) define statistical anxiety as "the feelings of anxiety encountered when taking a statistics course or doing statistical analyses" (p. 92). Onwuegbuzie, DaRos, and Ryan (1997) defined statistics anxiety as "a state-anxiety reaction to any situation in which a student is confronted with statistics in any form and at any time" (p. 28). Schau, Stevens, Dauphinee, \& Del Vecchio (1995) identified four components as a measure of attitude towards statistics: affect, cognitive competence, value, and difficulty. Zeidner (1991) indicates that "statistics anxiety may be construed as a particular form of performance anxiety characterised by extensive worry, intrusive thoughts, mental disorganization, tension, and psychological arousal" (p. 319). Zanakis \& Valenzi (1997) have identified six components as a measure of statistical anxiety and attitudes towards statistics: Student interest in and perceived worth of statistics, anxiety when seeking help for interpretation, computer usefulness and experience, understanding, test anxiety, and math anxiety. Finch \& Jameson (2007) state

...while statistics anxiety has been described in various ways over time, there are certain commonalities that appear to be present across definitions: psychological stress, fear of academic failure and feelings of incompetence (p. 185).

There is a body of research that indicates that there is a relationship between statistics anxiety and attitudes towards statistics with college students. DeVaney (2010) in a study of 27 oncampus ( 5 male, 22 female) and 93 online graduate students (18 male, 75 female) found that an inverse relationship between statistics and attitudes towards statistics with "...students in the online classes generally had higher levels of anxiety and less favorable attitudes towards statistics" (p. 9). Perepiczka, Chandler, \& Becerra (2011) in a study of 166 graduate students (30 male, 136 female) found a negative correlation between statistical anxiety and self-efficacy to learn statistics $(\mathrm{r}=-.679$ ), a positive correlation between self-efficacy to learn statistics and attitudes towards statistics $(r=.708)$, with statistics anxiety and attitudes towards statistics negatively and significantly correlated $(\mathrm{r}=-.832)$. Additionally, statistics anxiety and attitudes towards statistics were statistically significant predictors of self-efficacy to learn statistics. Dempster \& McCorry (2009) found that attitudes towards statistics and prior experience of mathematics and statistics were predictors of statistics assessment at an undergraduate level. Mills (2004) found that students who felt confident about being able to master material in an introductory statistics class exhibited very positive attitudes about statistics. Lacasse \& Chiocchio (2005) in a study of 68 students (14 male, 54 female) found a negative relationship between statistics anxiety and attitudes towards learning statistics $(r=-.41, p<.05)$. They indicate that "anxiety towards statistics negatively affects performance, interest, and desire to learn statistics in a psychometrics class" (p. 3).

\section{Gender differences in Statistics Anxiety}

Research on statistics anxiety with undergraduate college students has found mixed results. Some research has indicated that females experience greater levels of statistical anxiety than males. In a study of 40 postgraduate students (17 males, 21 female) enrolled in statistics at University of Wollongong, Baharun \& Porter (2009) found that males have significantly more 
confidence on their understanding of statistics topics (producing and interpreting scatterplots and correlations, writing meaningful paragraphs about variables, and less anxious about working with numbers) than females. Vahedi, Farrokhi \& Bevrani (2011) in a study of 300 undergraduate students (133 male, 165 female) from Tabriz University in Iran using the Statistics Anxiety Measure (SAM) found that "...female students reported more negative attitude towards class than male students” (p. 96). Papanastasiou \& Zembylas (2008) in a study of 472 undergraduate students $(87.3 \%$ female) who had completed a research methods class at the University of Cyprus found that males had lower levels of anxiety compared to females. Additionally, both males and females were most similar in their responses on the question "research is difficult" and had the highest discrepancy on the question "research scares me." Anxiety was positively correlated with the final grade in the class $(r=.292, p<.01)$. Similar results were obtained by DeCesare (2007) who found that "females reported feeling more anxious than males." (p. 363).

While the research above has found that females have more statistics anxiety than males, other research has found no gender differences in statistics anxiety (Lacasse \& Chiocchio, 2005; Onwuegbuzie, 2004; Zhang et al., 2012). In a study of 77 graduate students (19\% male, $81 \%$ female) in Taiwan, Hsiao \& Chiang (2011) found no difference between male and females with statistics anxiety on the Statistical Anxiety Rating Scale. Evans (2007) in a study of 115 undergraduate students (35 male, 80 female) from randomly selected statistics classes, found "students exhibited no significant change in attitudes and conceptions towards statistics over the course of the semester" (p. 26); however, significant correlations were found between course grades and initial and final student attitudes $(r=.203)$. Bui \& Alfaro (2011) in a study of 104 participants (23 males, 76 females) found that while most participants in their study had moderate statistics anxiety, no differences between males and females for all six subscales of the STARS. Similar results were obtained by Mji (2009) who found no gender differences in attitudes and attitudes towards statistics.

\section{OBJECTIVES}

The main objectives of this empirical study are:

a. To study gender differences in statistics anxiety with undergraduate college students, and

b. To study the relationship between statistics anxiety and course grades.

\section{RESEARCH QUESTIONS}

Given the mixed research on gender differences and anxiety towards statistics, it was felt that this study would contribute significantly to the body of literature. Of interest were the following research questions:

1. Would there be differences between male and female undergraduate college students with regard to statistics anxiety?

2. Would there be differences in statistics anxiety between students who have not taken a statistics class versus those who have taken a statistics class?

3. What is the correlation between statistics anxiety and course grades (GPA) for male and female undergraduate college students? 


\section{METHOD}

\section{Sample}

There were 156 undergraduate college students from the northeast United States who were surveyed. The students ranged in age from 17 to 50 (mean age $=22.17, \mathrm{SD}=6.77$ ). There were 48 males (30.8\%) and 107 females (68.6\%) in the study, with 1 student not disclosing their gender. Grade point average (GPA) for males ranged from 2.20 to 4.00 (Mean = 3.18, SD = .46) and for females ranged from 2.00 to 4.00 (Mean GPA = 3.31, SD = .47). Students represented a variety of academic disciplines, ranging from social sciences, nursing, business, exercise science, humanities, undecided, and other. Two students did not disclose their major.

With regard to number of statistics classes taken, $25(52.1 \%)$ of males had taken no statistics classes, $22(45.8 \%)$ had taken one statistics class, and $1(2.1 \%)$ had taken two statistics classes. With females, $44(41.1 \%)$ had taken no statistics classes, 58 (54.2\%) had taken one statistics class, and $5(4.7 \%)$ had taken two statistics classes.

\section{Measuring Tools}

Students were administered a demographic information questionnaire that asked about age, gender, major, grade point average (GPA), and number of prior statistics classes taken.

\section{Statistical Anxiety Rating Scale (STARS)}

The Statistical Anxiety Rating Scale (STARS) was administered to the students. The scale was developed by Cruise, Cash \& Bolton (1985) and "was developed to measure statistical anxiety" (p. 92). The STARS consists of 51 items which represent 6 subscales. For the present study, three sub-scales of the STARS were used: Worth of Statistics, Computation Self-Concept, and Test and Class Anxiety (Table 1).

Table 1. Descriptions of the Subscales Used in the Current Study

\begin{tabular}{lcc}
\hline Subscale Descriptions and Examples & $\begin{array}{c}\text { Number } \\
\text { of Items }\end{array}$ & $\begin{array}{c}\text { Range } \\
\text { of scores }\end{array}$ \\
\hline $\begin{array}{l}\text { Worth of Statistics } \\
\text { "This factor has to do with the student's }\end{array}$ & 16 & $16-80$ \\
perception of the relevance of statistics" & & \\
(Cruise, Cash, \& Bolton, 1985, p.93). & & \\
$\quad$ I feel statistics is a waste. & & \\
$\quad$ I don't want to learn to like statistics. & & \\
$\quad$ Statistics takes more time than it's worth.
\end{tabular}

\section{Computation Self-Concept}

"This factor involves anxiety experienced when

doing mathematical problems as well as the

student's self-perception of his/her ability to

understand and calculate statistics"

(Cruise, Cash, \& Bolton, 1985, p. 93).

I don't have enough brains to get through statistics.

I'm too slow in my thinking to get through statistics. 
Statistics isn't really bad. It's just too mathematical.

Test and Class Anxiety

"This factor deals with the anxiety involved

when taking a statistics class or test"

(Cruise, Cash, \& Bolton, 1985, p. 93)

Studying for an examination in a statistics class.

Enrolling in a statistics course.

Doing the homework for a statistics course.

Subjects respond to the items on a 5 point scale, where $1=$ strongly disagree, $5=$ strongly agree For the Test and Class Anxiety subscale, subjects respond on a 5 point scale, where $1=$ No anxiety and $5=$ High anxiety. Based on the scoring provided by Cruise, Cash, \& Bolton (1985), a low score on each subscale indicates low anxiety, while as a high score on each subscale indicates high anxiety. Keeley, Zayac, \& Correia (2008) using Cronbach's alpha report the reliability of the Worth of Statistics scale to be .94 , Computation Self-Concept to be .88 , and Test and Class Anxiety Scale to be .88 .

In order to obtain additional information on statistics anxiety, students were asked the following open-ended question, "What are your feelings/reactions to taking or having taken a statistics class at the college?" Gal \& Ginsburg (1994) indicate that a minimum requirement for an instrument that measures beliefs and attitudes should combine Likert-type items with open-ended questions, where students can explain their beliefs, feelings, concerns, emotional responses, and attitudes towards the subject. 


\section{RESULTS}

\section{Gender Differences in Statistics Anxiety}

No significant gender differences were obtained overall for the Worth of Statistics subscale, $F$ (1, $142)=.08, \mathrm{p}>.05$. For overall Computation Self-Concept subscale, no significant gender differences were obtained, $F(1,147)=.83, \mathrm{p}>.05$. Significant gender differences were obtained with the Test and Class Anxiety subscale, $F(1,149)=13.73, \mathrm{p}<.01$, indicating that females had a more negative attitude and higher anxiety on this subscale than males (Table 2).

Table 2. Means, Standard Deviations, and $F$ Test Results for Males and Females for the Three Subscales of the STARS

\begin{tabular}{lccc}
\hline & $\begin{array}{c}\text { Male } \\
(\mathrm{n}=48)\end{array}$ & $\begin{array}{c}\text { Female } \\
(\mathrm{n}=107)\end{array}$ & $F$ \\
Worth of Statistics & 53.38 & 54.18 & .08 \\
Mean & 16.21 & 15.77 & \\
SD & & & .83 \\
& & & \\
Computation Self-Concept & 22.63 & 23.66 & \\
Mean & 6.81 & 6.15 & $13.73 * *$ \\
SD & & & \\
Test and Class Anxiety & & & \\
Mean & 20.21 & 25.48 & \\
SD & 6.70 & 8.53 & \\
\hline$* * p<.01$ & &
\end{tabular}

A closer examination of the individual items of the STARS (Table 3) indicates that females scored significantly higher than males for the following item of the Computational Self-Concept subscale, "I haven't had mathematics in a long time. I know I'll have problems getting through statistics." Females also scored higher than males on the following items of the Test and Class Anxiety Subscale: "Walking in a classroom to take a test", "Doing a final examination in a statistics course" "Studying for an examination in a statistics course" "Waking up in the morning on the day of a statistics test" and "Finding that another student in class got a different answer than you did to a statistical problem."

Table 3. Means, Standard Deviations, and $F$ Test for Males and Females for the Three Subscales of the STARS.

\begin{tabular}{|l|l|l|l|l|l|}
\hline Items for the STARS Subscale & \multicolumn{2}{|l|}{$\begin{array}{l}\text { Males } \\
(\mathrm{n}=48)\end{array}$} & \multicolumn{2}{l|}{$\begin{array}{l}\text { Females } \\
(\mathrm{n}=107)\end{array}$} & $F$ \\
\hline & Mean & SD & Mean & SD & \\
\hline Worth of Statistics Subscale & & & & & \\
\hline I feel statistics is a waste. & 3.47 & 1.25 & 3.39 & 1.20 & NS \\
\hline $\begin{array}{l}\text { I wish the statistics requirements would be removed } \\
\text { from my academic program. }\end{array}$ & 3.20 & 1.23 & 3.28 & 1.31 & NS \\
\hline
\end{tabular}




\begin{tabular}{|c|c|c|c|c|c|}
\hline $\begin{array}{l}\text { I am never going to use statistics, so why should I } \\
\text { have to take it? }\end{array}$ & 3.43 & 1.20 & 3.34 & 1.32 & NS \\
\hline $\begin{array}{l}\text { I don't understand why someone in my field needs } \\
\text { statistics. }\end{array}$ & 3.52 & 1.25 & 3.37 & 1.33 & NS \\
\hline Statistics takes more time than it's worth. & 3.31 & 1.23 & 3.35 & 1.25 & NS \\
\hline Statistics is a grind, I could do without. & 3.31 & 1.18 & 3.21 & 1.27 & NS \\
\hline $\begin{array}{l}\text { Since I am by nature a subjective person, the } \\
\text { objectivity of statistics is inappropriate for me. }\end{array}$ & 3.33 & 1.20 & 3.49 & 1.16 & NS \\
\hline I don't want to learn to like statistics. & 3.31 & 1.30 & 3.44 & 1.24 & NS \\
\hline I can't tell you why but I just don't like statistics. & 3.22 & 1.34 & 3.27 & 1.25 & NS \\
\hline $\begin{array}{l}\text { I don't see why I have to clutter my head up with } \\
\text { statistics. It has no significance to my life work. }\end{array}$ & 3.66 & 1.52 & 3.58 & 1.50 & NS \\
\hline $\begin{array}{l}\text { I wonder why I have to do all these things in } \\
\text { statistics when in actual life I'll never use them. }\end{array}$ & 3.37 & 1.31 & 3.44 & 1.25 & NS \\
\hline $\begin{array}{l}\text { Affective skills are important in my profession that } \\
\text { I do not want to clutter my thinking with something } \\
\text { as cognitive as statistics. }\end{array}$ & 3.10 & 1.20 & 3.40 & 1.17 & NS \\
\hline $\begin{array}{l}\text { I lived this long without knowing statistics. Why } \\
\text { should I learn it now? }\end{array}$ & 3.35 & 1.26 & 3.37 & 1.27 & NS \\
\hline $\begin{array}{l}\text { Statistical figures are not fit for human } \\
\text { consumption. }\end{array}$ & 3.33 & 1.35 & 3.62 & 1.18 & NS \\
\hline $\begin{array}{l}\text { Statistics is for people who have a natural learning } \\
\text { towards mathematics. }\end{array}$ & 3.08 & 1.71 & 3.09 & 1.28 & NS \\
\hline $\begin{array}{l}\text { Statistics is worthless to me since it is empirical } \\
\text { and my area of specialization is philosophical. }\end{array}$ & 3.29 & 1.32 & 3.51 & 1.28 & NS \\
\hline \multicolumn{6}{|l|}{ Computation Self-Concept Subscale } \\
\hline $\begin{array}{l}\text { I can't even understand } 7^{\text {th }} \text { and } 8^{\text {th }} \text { grade } \\
\text { mathematics, how can I possibly do statistics? }\end{array}$ & 3.66 & 1.52 & 3.58 & 1.50 & NS \\
\hline $\begin{array}{l}\text { I could enjoy statistics if it weren't so } \\
\text { mathematical. }\end{array}$ & 3.25 & 1.20 & 3.33 & 1.29 & NS \\
\hline $\begin{array}{l}\text { Since I have never enjoyed mathematics, I don't } \\
\text { see how I can enjoy statistics. }\end{array}$ & 3.35 & 1.31 & 3.29 & 1.36 & NS \\
\hline I don't have enough brains to get through statistics. & 3.52 & 1.50 & 3.63 & 1.44 & NS \\
\hline $\begin{array}{l}\text { Statistics isn't really bad. It's just too } \\
\text { mathematical. }\end{array}$ & 3.04 & 1.21 & 3.27 & 1.20 & NS \\
\hline $\begin{array}{l}\text { I'm too slow in my thinking to get through } \\
\text { statistics. }\end{array}$ & 3.31 & 1.43 & 3.57 & 1.36 & NS \\
\hline $\begin{array}{l}\text { I haven't had mathematics in a long time. I know } \\
\text { I'll have problems getting through statistics. }\end{array}$ & 2.34 & 1.20 & 2.86 & 1.40 & $4.98 *$ \\
\hline
\end{tabular}




\begin{tabular}{|l|l|l|l|l|l|}
\hline & & & & & \\
\hline Test and Class Anxiety Subscale & & & & & \\
\hline Walking into the classroom to take a statistics test. & 2.70 & 1.24 & 3.75 & 1.25 & $22.94^{* *}$ \\
\hline Doing the final examination in a statistics course. & 3.23 & 1.18 & 4.21 & 1.12 & $23.78^{* *}$ \\
\hline Studying for an examination in a statistics course. & 2.82 & 1.12 & 3.48 & 1.24 & $9.48^{* *}$ \\
\hline Doing the homework for a statistics course. & 2.36 & 1.14 & 2.53 & 1.30 & NS \\
\hline $\begin{array}{l}\text { Waking up in the morning on the day of a statistics } \\
\text { test. }\end{array}$ & 2.34 & 1.14 & 3.24 & 1.38 & $15.40^{* *}$ \\
\hline Enrolling in a statistics course. & 2.02 & 1.17 & 2.45 & 1.53 & NS \\
\hline $\begin{array}{l}\text { Going over an examination in statistics after it has } \\
\text { been graded. }\end{array}$ & 2.29 & 1.23 & 2.61 & 1.54 & NS \\
\hline $\begin{array}{l}\text { Finding that another student in class got a different } \\
\text { answer than you did to a statistical problem. }\end{array}$ & 2.61 & 1.15 & 3.13 & 1.35 & $5.12^{*}$ \\
\hline
\end{tabular}

$* \mathrm{p}<.05 * * \mathrm{p}<.01$

\section{Gender, Statistics Classes and Statistics Anxiety}

An examination of Table 4 indicates that no significant differences were obtained in statistics anxiety between students who had not taken a statistics class versus those who had taken a statistics class. Females who had completed one or more statistics classes tended to have significantly higher Test and Class Anxiety than males.

Table 4. Means (Standard Deviations) for Gender and Statistics Classes Taken for Three Subscales of the STARS

\begin{tabular}{|c|c|c|c|}
\hline & STARS Subscales & & \\
\hline $\begin{array}{ll}\text { Statistics } & \text { Class } \\
\text { Taken? } & \end{array}$ & Worth of Statistics & $\begin{array}{l}\text { Computation Self- } \\
\text { Concept }\end{array}$ & $\begin{array}{l}\text { Test and Class } \\
\text { Anxiety }\end{array}$ \\
\hline $\begin{array}{l}\text { No Statistics Classes } \\
\text { Males } \\
\text { Females }\end{array}$ & $\begin{array}{l}51.72(15.20) \\
51.97(16.11)\end{array}$ & $\begin{array}{l}21.56(6.74) \\
23.27(6.49)\end{array}$ & $\begin{array}{l}21.56(7.10) \\
25.21(9.75)\end{array}$ \\
\hline $\begin{array}{l}\text { One or More } \\
\text { Statistics Classes } \\
\text { Males } \\
\text { Females }\end{array}$ & $\begin{array}{l}55.27(11.45) \\
55.63(15.51)\end{array}$ & $\begin{array}{l}23.69(6.87) \\
23.91(5.97)\end{array}$ & $\begin{array}{l}18.86(6.14) \\
25.66(7.66)\end{array}$ \\
\hline
\end{tabular}

\section{Statistics Anxiety and Course Grades (GPA) by Gender}

For males, no significant correlations were obtained between the three subscales of the STARS and course grades. For females, significant correlations were obtained for only Worth of Statistics and course grades $(\mathrm{r}=.230, \mathrm{p}<.05)$ and Computation Self-Concept and course grades $(\mathrm{r}=.226, \mathrm{p}<.05)$. 


\section{Gender Differences in Statistics Anxiety with Undergraduate College Students}

\section{DISCUSSION}

This study investigated gender differences in statistics anxiety with undergraduate college students. Three significant findings emerged from the study:

- There were no significant differences between males and females for Worth of Statistics subscale and Computation Self-Concept subscale; however, females had a more negative attitude for the Test and Anxiety subscale than males.

- There were no significant differences in statistics anxiety between students who had not taken a statistics class versus those who had taken a statistics class.

- For males, no significant correlations were obtained between statistics anxiety and course grades. For females, significant correlations were obtained between Worth of Statistics, Computation Self-Concept and course grades.

The lack of gender differences in the Worth of Statistics and Computation Self-Concept subscales is intriguing. In previous research, Hamid \& Sulaiman (2014) found that psychology majors and minors enrolled in a statistics class tended to have the highest level of anxiety on the STARS for Fear of Statistics Teachers and the lowest level of anxiety for Worth of Statistics. They state that "this could be due to the perceived importance of statistics which is a required course for them" (p. 63). Lui, Onwuegbuzie, \& Meng (2011) found that Chinese students in their study reported the lowest anxiety on the Test and Class anxiety dimension, and high scores on the Worth of Statistics dimension. They attribute the results to the Chinese students' strong mathematical background and conclude that the high Worth of Statistics score obtained by the students "...might be related to the use of statistics in the real world in China..." (p. 40). Firmin \& Proemmel (2008) state that "...undergraduate students tend not to see the day-to-day relevance of statistics to life, but it is relevant" (p. 19).

The importance of the Worth of Statistics (which includes positive and favorable attitudes) is exemplified in the response to the open-ended question by a male student who states:

"When I first entered college, I did not understand what statistics truly meant. After talking to many professors, I knew that statistics was going to be my friend in my future. I was given the opportunity to understand statistics, which I knew would be beneficial for my research in the future. Statistics is not scary to me, it is necessary."

Gender differences were obtained for the Test and Class Anxiety subscale, with females experiencing greater statistics anxiety than males. Along those lines, Mills (2004) found that males indicated feeling more confident than females that they could master statistics, were not afraid of statistics, and that they could learn statistics. Previous research by DeCesare (2007) and Vahedi, Farrokhi \& Bevrani (2011) found that females had more statistics anxiety than males.

An examination of the items on the Test and Class Anxiety subscale indicates that they measure anxiety involved when taking a statistics class or test (e.g., studying for an examination in a statistics class, doing a final examination in a statistics class). In statistics classes, college professors often encounter fear and negative responses from their students on this dimension 
which include statements like "I am so nervous in this class", "I feel so stupid in the class", "My friend had a really tough time in the class", and "This class is going to be really difficult". Responses to the open-ended question from the students below indicate similar negative and unfavorable attitudes which encompass this subscale.

"When I think about taking a stats class I am intimidated and feel like I will be overwhelmed with the content." (Male student)

"When I hear the term, "statistics", I become physically tense; stiffening up because of the anxiety I feel. Statistics is the "big, scary monster" course every student must pass in order to earn their degree. I have heard more negative feedback regarding statistics than positive." (Female student)

"I have not yet taken Statistics, but it literally makes me short of breath and I can feel an overwhelming sense of anxiety." (Female student)

"When I was enrolled in statistics I was very nervous because of how hard it was for my friends." (Female student)

"When I hear the term "statistics" I feel instantly anxious and really nervous. I feel very stressed out. Whenever I hear anyone talking about a stats class it is almost always negative." (Female student)

"Even thinking about statistics made me feel stressed and incredibly anxious.

Once I began class, however, I began to gain a bit of confidence and to realize that with hard work, passing was possible." (Female student)

An examination of the responses above indicates that students experienced greater anxiety, pressure, nervousness, and stress about entering a classroom and taking/completing a statistics class. Female students also questioned their abilities/performance in a statistics class, and in general exhibited a more negative and unfavorable attitude towards statistics. It can be speculated that students who have negative attitudes (and unfavorable attitudes) also experience anxiety and low efficacy towards statistics. Perepiczka, Chandler, \& Becerra (2011) indicate that "decreasing anxiety among graduate students is vital to developing high levels of self-efficacy towards statistics" (p. 105). Thus, it is recommended that statistics instructors monitor the levels of anxiety and apprehension experienced by their students and devise instructional strategies to deal with and/or reduce that anxiety experienced in their statistics class (Gal \& Ginsburg, 1994; Zhang et al, 2012).

No differences were obtained in statistics anxiety between students who had not taken a prior statistics class and those who had completed a prior statistics class. Zhang et al., (2012) found that medical students with higher levels of research experience and statistical education tended to have more positive attitudes. Thus, it is recommended that students be provided research experience in their classes. 
For males, no significant correlations were obtained between statistics anxiety and course grades. For females, significant positive correlations were obtained between course grades and Worth of Statistics and Computational Self-Concept. Wilson (1997) found no significant relationship between anxiety and expected grade. Onwuegbuzie (1995) found an inverse relationship between anxiety and performance $(\mathrm{r}=-.62, \mathrm{p}<.05)$. Perney \& Ravid (1990) also found "...course grades were not related to attitudes towards statistics, math self-concept, or attitudes towards test" (p. 11). In contrast, Cherney \& Cooney (2005) found positive correlations between course grades and statistics perceptions $(r=.28, \mathrm{p}<.001)$. DeCesare $(2007)$ who found a significant relationship between anxiety and course grade, indicates using various techniques for dealing with statistics anxiety like research projects that use real life data, group activities and projects, and daily or weekly homework assignments to mention a few. Students across the curriculum should be encouraged to see how their statistics class will be useful, relevant and valuable for them in the future and encouraged to expend more energy into the classes (Wigfield \& Eccles, 1992).

A question of interest is whether anxiety experienced in a statistics class can be decreased by using diverse resources and instructional techniques? Zhang et al., (2012) state

Improving students' attitudes toward statistics may have a direct positive effect on learning statistics. Accordingly, an important issue for teachers is how to improve students' attitudes toward statistics, especially, how to reduce the fear and anxiety in learning statistics (p. 7).

\section{Techniques for Decreasing Statistics Anxiety}

Quinn (2006) found that teaching methods that demonstrated various statistical techniques decreased statistical anxiety with social work students. Along those lines “...giving students the opportunity to discuss the statistics tests through their journal writing ups, group presentations and SPSS discussions allowed to immerse themselves further into understanding the statistical tests, thus potentially increasing their comfort with the material and further reducing anxiety" (p. 170). Schau (2003) recommends suggestions that may help students in a statistics class. Some of these include: encouraging students who have debilitating anxiety or a lack of confidence to seek assistance, bringing a positive attitude to the course, stressing that a statistics course is not a math course, teaching that statistics is valuable, recognizing student's positive and negative attitudes, using humor to teach statistics, assessing student attitudes, and holding classroom discussions about attitudes.

D'Andrea and Waters (2002) found that the use short fictional stories to teach statistics reduced student's statistical anxiety, but it did not change their attitude towards statistics. Firmin \& Proemmel (2008) discuss strategies that faculty can use for reducing students' statistics anxiety in their classes. Some of these include: spending class time helping students see connections between learning statistics and their professional futures, making statistics more interesting, using technology to enhance student experiences, using a conceptual rather than computational approach, using classroom exercises and demonstrations, journaling, and holding study sessions and tutorials to reduce student statistics anxiety. Future research should examine if diverse 
pedagogical techniques for learning statistics could lower anxiety, especially with female students.

While this study would contribute significantly to the literature, we suggest that further research should examine questions like:

(a) What is the relationship between students perception of self-efficacy and statistics anxiety?

(b) Would students who have a more extensive mathematics background have lower statistics anxiety and more positive attitudes towards statistics?

(c) How can educators work with students who have lower levels of confidence and high levels of statistics anxiety, so that the course is rigorous, useful, interesting and a valuable experience? (DeCesare, 2007).

\section{CONCLUSION}

Caution should be used in interpreting the results and the study should be conducted with a larger population of undergraduate college students. However, the results of this study will assist educators and researchers in identifying variables that may assist students be successful in their statistics class.

\section{REFERENCES}

1. Baharun, N., \& Porter, A. (2009). Removing the angst from statistics. Centre for statistical and Survey methodology. University of Wollongong, Working Paper 26-09.

2. Bui, N. H., \& Alfaro, M, A. (2011). Statistics anxiety and science attitudes: Age, gender, and ethnicity factors. College Student Journal, 45(3), 573-585.

3. Cherney, I. D., \& Cooney, R. R. (2005). Predicting student performance in a statistics course using the Mathematics and Statistics Perception Scale (MSPS). Transactions of the Nebraska Academy of Science, 30, 1-8.

4. Cruise, J. R., Cash, R. W., \& Bolton, L. D. (1985). Development and validation of an instrument to measure statistical anxiety. Paper presented at the Annual Meeting of the American Statistical Association, Proceedings of the Section on Statistical Education, 92-97.

5. D'Andrea, L., and Waters, C. (2002). Teaching statistics using short stories: Reducing anxiety and changing attitudes. Paper presented at the Sixth International Conference on Teaching Statistics (ICOTS), Cape Town, South Africa.

6. DeCesare, M. (2007). Statistics Anxiety' Among Sociology Majors: A First Diagnosis and Some Treatment Options. Teaching Sociology, 35(4), 360-367.

7. Dempster, M., \& McCorry, N. K., (2009). The role of previous experience and attitudes towards statistics in statistics assessment outcomes among undergraduate psychology students. Journal of Statistics Education, 17(2), Retrieved January 4, 2014, from www.amstat.org/publications/jse/v17n2/dempster.html.

8. DeVaney, T. A. (2010). Anxiety and attitude of graduate students in on-campus vs. online statistics courses. Journal of Statistics Education, 18(1), 1-15.

9. Evans, B. (2007). Student attitudes, conceptions, and achievement in introductory undergraduate college statistics. The Mathematics Educator, 17(2), 24-30. 
10. Finch, H., \& Jameson, M. M. (2007). Prior statistics coursework and student expectations of a graduate statistics class. In Festschrift in honor of Mir Masoom Ali, (pp.185-189). Muncie, IN: Ball State University.

11. Firmin, M., \& Proemmel, E. (2008). Towards remediating undergraduate students' statisticophobia. College Teaching Methods \& Styles Journal, 4(4), 17-20.

12. Gal, I., \& Ginsburg, L. (1994). The role of beliefs and attitudes in learning statistics: Towards an assessment framework. Journal of Statistics Education [Online], 2(2). Retrieved on March 3, 2014 from www.amstat.org/publications/jse/v2n2/gal.html

13. Galli, S., Ciancaleoni, M., Chiesi, F., \& Primi, C. (2008). Who failed introductory statistics? Paper presented at International Congress on Mathematical Education, Mexico. Retrieved on March 8, 2014 from http://tsg.icme11.org/document/get/526

14. Hilton, S.C., Schau, C., \& Olsen, J. A. (2004). Survey of attitudes towards statistics: Factor structure invariance by gender and by administration time. Structural Equation Modeling, 11(1), 92-109.

15. Hamid, H. S. A., \& Sulaiman, M. K. (2014). Statistics anxiety and achievement in a statistics course among psychology students. International Journal of Behavioral Science, 9(1), 55-66.

16. Hsiao, T-Y., \& Chiang, S. (2011). Gender differences in statistics anxiety among graduate students learning English as a foreign language. Social Behavior and Personality, 39(1), 41-42.

17. Keeley, J., Zayac, R., \& Correia, C. (2008). Curvilinear relationships between statistics anxiety and performance among undergraduate students: Evidence for optimal anxiety. Statistics Education Research Journal, 7(1), 4-15.

18. Lacasse, C., \& Chiocchio, F. (2005). Anxiety towards statistics: Further developments and issues. Presentation at the 66th Annual Convention of the Canadian Psychological Association, Montreal, Quebec, Canada.

19. Lui, S., Onwuegbuzie, A. J., \& Meng, L. (2011). Examination of Examination of the score reliability and validity of the statistics anxiety rating scale in a Chinese population: Comparisons of statistics anxiety between Chinese college students and their Western counterparts. Journal of Educational Enquiry, 11(1), 29-42.

20. Mills, J. D. (2004). Students' attitudes towards statistics: implications for the future. College Student Journal, 38(3), 349-361.

21. Mji, A. (2009). Differences in university students' attitudes and anxiety about statistics. Psychological Reports, 104(3), 737-744.

22. Mji, A., \& Onwuegbuzie, A. J. (2004). Evidence of score reliability and validity of the Statistical Anxiety Rating Scale among Technikon students in South Africa. Measurement and Evaluation in Counseling and Development, 36, 238-251.

23. Onwuegbuzie, A. J. (1995). Statistics test anxiety and female students. Psychology of Women Quarterly, 19, 413-418. 
24. Onwuegbuzie, A. J. (2004). Academic procrastination and statistics anxiety. Assessment \& Evaluation in Higher Education, 29(1), 3-19.

25. Onwuegbuzie, A.J., DaRos, D.A., \& Ryan, J. (1997). The components of statistics anxiety: A phenomenological study. Focus on Learning Problems in Mathematics, 19(4), $11-35$.

26. Onwuegbuzie, A. J., \& Wilson, V. A. (2003). Statistics anxiety: nature, etiology, antecedents, effects, and treatments - a comprehensive review of the literature. Teaching in Higher Education, 8(2), 195-209.

27. Papanastasiou, E. C., \& Zembylas, M. (2008). Anxiety in undergraduate research methods courses: its nature and implications. International Journal of Research \& Methods in Education, 31(2), 155-167.

28. Perepiczka, M., Chandler, N., \& Becerra, M. (2011). Relationship between graduate students' statistics self-efficacy, statistics anxiety, attitude towards statistics, and social support. The Professional Counselor: Research and Practice, 1(2), 99-108.

29. Perney, J., \& Ravid, R. (1990). The relationship between attitudes towards statistics, math self-concept, test anxiety and graduate students' achievement in an introductory statistics class. Paper presented at the Annual Meeting of the American Educational Research Association, Boston, MA.

30. Quinn, A. J. (2006). Reducing social work students' statistical anxiety. Academic Exchange Quarterly, 10(2), 167-171.

31. Schau, C. (2003). Students' attitudes: The "other" important outcome in statistics education. Paper Presentation at the Joint Statistical Meetings, San Francisco, CA.

32. Schau, C., Stevens, J. J., Dauphinee, T. L., \& Del Vecchio, A. (1995). The developmental validation of the Survey of Attitudes Toward Statistics. Educational and Psychological Measurement, 55, 868-875.

33. Vahedi, S., Farrokhi, F., \& Bevrani, H. (2011). A confirmatory factor analysis of the structure of Statistics Anxiety Measure: An examination of four alternative models. Iran Journal of Psychiatry, 6(3), 92-98.

34. Wigfield, A., \& Eccles, J. (1992). The development of achievement task values: A theoretical analysis. Developmental Review, 12, 265-310.

35. Williams, A. S. (2010). Statistics anxiety and instructor immediacy. Journal of Educational Statistics, 18(2), 1-18.

36. Wilson. V. (1997). Factors related to anxiety in the graduate statistics classroom. Paper presented at the Annual Meeting of the Mid-South Educational Research Association, Memphis, TN.

37. Zanakis, S. H., \& Valenzi, E. R. (1997). Student anxiety and attitudes in business statistics. Journal of Education for Business, 73(1), 10-16.

38. Zeidner, M. (1991). Statistics and mathematics anxiety in social science students: Some interesting parallels. British Journal of Educational Psychology, 61, 319-328.

39. Zhang, Y., Shang, L., Wang, R., Zhao, Q., Li, C., Xu, Y., \& Su, H. (2012). Attitudes towards statistics in medical postgraduates: measuring, evaluating and monitoring. BMC Medical Education, 12(117), 1-8. 